\title{
Changes in the electron paramagnetic resonance spectra of albumin-associated spin-labeled stearic acid as a diagnostic parameter of colorecta! cancer
}

\author{
Zhongchao Liu, Wenyi Zhang, Saijun Fan, Liang Wang and Ling Jiao*
}

\begin{abstract}
Background: With more than 940,000 new colorectal cancer cases worldwide _ - $-\mathrm{h}$ year, , nere is no better way for colorectal cancer routine screening. The aim of this study was to investigate whet. the fatty acid binding to albumin is detectably and significantly altered in colorectal cancer patier:s w ien compared with healthy people, in order to find a better way for colorectal cancer diagnosis.

Methods: One hundred and forty-one patients operatively treated 1 -nlore_tal cancer were included in the examination, and 180 healthy people were also enrolled as controls. Esm, nercial 16-doxyl stearic acid was used as spin probe. Serum albumin was analyzed by electron paramannetic re-onance (EPR) with spin probe. Discriminant analysis was carried out using the measured EPR spectra ' "SF_ 20.0.

Results: Of the original grouped cases, $89.4 \%$ were crillectly 'acsified. Of the cross-validated grouped cases, 86.9\% were correctly classified. Using Fisher linear discrimii. nt ancilysis we were able to develop a mathematical model allowing for identification of colorectal cancer $r$ atients xed on five values (both relative intensity and peak width) which are obtained from the EPR spectrum.

Conclusions: Cancer-associated alteratio is to albur in can be assessed by spin-label EPR. The potential applications for this diagnostic technique are signific $7 t$ and represent a cost-effective means for screening patients with cancer. Spin probe for diagnosis of colorectal car...... iight be a useful tool and further studies should take place in order to investigate all stages of colorectá _ -or patients.
\end{abstract}

Keywords: Colorectal canc $f_{-1,} L$;crim inant analysis, EPR/ESR, Spin probe

\section{Background}

Colorectal cancer is the s. und most common cancer and the second. $x$ s common cause of death by cancer [1]. The clin: -1 SL. o of the disease at diagnosis often determinf the nrognosis and survival rate of a patient with colorec ' cancer [2]. If the colorectal cancer patient could be diagnosed at an early stage, they will have a better treatment than if diagnosed at an advanced stage. However, insufficient evidence concerning prognostic and predictive value exists for other molecular factors such as thymidylate synthase, microsatellite instability (MSI), p-53 and K-ras. [3].

\footnotetext{
* Correspondence: ljiao.irm@163.com

Department of Radiation Protection Center, Institute of Radiation Medicine, Chinese Academy of Medical Sciences\&Peking Union Medical College, Tianjin Key Laboratory of Molecular Nuclear Medicine, 238 Baidi Road, Nankai District, Tianjin 300192, P.R. China
}

Human serum albumin (HSA) is the main component for transport of a variety of peptides and of waterinsoluble fatty acids (FA) in the serum [4]. Its remarkable ability for binding FA has motivated our group to use spin-labeled derivatives of stearic acids to monitor conformational changes around its binding sites [5]. Seven long-chain FA binding sites have been described so far [6]. Proteins released from tumor cells are able to bind to albumin and thus lead to a modification of its structure and function [6,7]. As a consequence, the binding and transport capacities for FA are also changed. These changes can be detected by electron paramagnetic resonance (EPR)/electron spin resonance spectroscopy $[8,9]$. EPR is suitable for the determination of functional characteristics of plasma proteins $[7,10]$. EPR spectroscopy detects radicals that are, in the case of HSA,

\section{Biomed Central}


introduced artificially using long-chain FA that have a stable radical (doxyl) chemically attached and by analyzing how these spin-labeled FA bind to albumin [7]. Use of this technique with 16-doxyl stearic acid (2-(14carboxytetradecyl)-2-ethyl-4, 4-dimethyl-3-oxazolidinyloxy) as spin probe has previously demonstrated cancer-specific alterations in albumin conformation [10,11]. We used EPR spectroscopy to investigate the diagnostic utility of serum albumin conformation analysis in patients with colorectal cancer and chronic disease.

\section{Methods}

\section{Samples}

All patients who presented to department of surgical oncology PLA People's Liberation Army General Hospital had been pathologically diagnosed with colorectal cancer during the study period. Samples were collected from 141 patients with colorectal cancer and 180 blood donors and other volunteers known to be in good health. All patients provided their consent for participation in the study (approved by Institute of Radiation Medicine Chinese Academic of Medical Sciences ethics committee). Table 1 shows the detailed information. Blood was obtained by standard venipuncture techniques and cr:lected without any additive. After clotting, serum va separated by centrifugation for 10 minutes, isolated, a. ' then stored at $-20{ }^{\circ} \mathrm{C}$ before analysis.

\section{Sample preparation}

Commercial 16-doxyl stearic acid (Sigma- 'Aric'، GmbH, Munich, Germany) was used as sp nrobe. This compound was chosen because of the extre,nt,y high binding constant of albumin for ste ric icid $5.9 \times 10^{7} \mathrm{~L} / \mathrm{mol}$ ), generally leading to $99.9 \%$ hir is u chis spin probe to albumin. Here we used defin c concentration of spin probe-pure ethanol comp 'nds to perform the experiment. Each aliqu ot receives a defined concentration of spin probe-pure e $e^{\prime}$ nol compounds with $50 \mu \mathrm{L}$ of serum and then trins. rmes .o a microliter shaker for 10 minutes at $25^{\circ} \mathrm{C} \mathrm{cov}-u_{i}$, parafilm. The aliquots were then transferred into cap ary glass tubes for analysis within the EPR spectrometer. Each sample was measured three times.

\section{Sample measurement}

We measured the EPR spectra of each sample with a commercially available EPR spectrometer (Bruker EMX

Table 1 Demographic information for patients evaluated in the study

\begin{tabular}{llll}
\hline Group & Median age (years) & Age range & Female (\%) \\
\hline I & 72 & $40-92$ & 62 \\
II & 53 & $27-87$ & 46 \\
\hline
\end{tabular}

Group I, patients with colorectal cancer just after operation ( $n=141)$; Group II, healthy volunteers $(n=180)$.
A300, Ettlingen, Germany). The spectrometer operating conditions adopted during the experiments are given in Table 2.

As the EPR spectrum is comprised of 1024 data points, we just used Matlab (version 7.0 Math Works Natick, Massachusetts, U.S.A.) to make up a small program to simulate the spectrum curve using least-square fitting and calculated the peak width snc the relative intensity.

\section{Statistical analysis}

Gammerman and colleague [12] and de Noo and colleagues [13] described $a{ }^{\prime} \cdot \mathrm{ub}_{1}$ ' 'roc,-validatory implementation of linear discrinina. inalysis for the calibration of a diagnostic rule $\mathrm{r}_{\mathrm{a}}$. + on a single spectrum per patient (and for a single fractic. tion). Due to non-normal distribution of th rav data, a logarithmic transformation was needed. To pe. it cumparisons with other studies, results are pre uted a, means with the standard deviation obtained at. $e_{1}$, ne Ln transformation. Comparisons or correlations were evaluated by using non-parametric tests (Kı. kall Wallis one-way variance analysis or Spearman 'nk test, respectively) on the raw data, and by means of St ,dent's $t$ test on normalized data. Discriminant analysis was carried out using the measured EPR spectra by SPSS 20.0 (IBM, Armonk, New York, U.S.A). Selected values for variables such as relative intensity and peak widths can then be used to estimate the biophysical characteristics of the 16-doxyl stearic acid spin label. The selected parameters are shown in Figure 1. The analysis was performed using the option of the 'equal prior probability' to assign the subjects to groups.

All the predictor variables were subjected to stepwise discriminant function analysis, which has the potential to optimally separate the two groups; furthermore, the statistical significance was assessed using Wilks' lambda. The variables having the higher discriminant function coefficient were included in the discriminant function for developing the formula.

Table 2 The spectrometer operating conditions adopted during the experiment

\begin{tabular}{cc}
\hline Central field & $3515 \mathrm{G}$ \\
Sweep width & $150 \mathrm{G}$ \\
Microwave frequency & $9.864 \mathrm{GHz}$ \\
Microwave power & $15.94 \mathrm{MW}$ \\
Modulation frequency & $100 \mathrm{KHz}$ \\
Modulation amplitude & $10 \mathrm{G}$ \\
Receiver gain & 20 \\
Sweep time & $20 \mathrm{~s}$ \\
Time constant & $0.16 \mathrm{~ms}$ \\
\hline
\end{tabular}




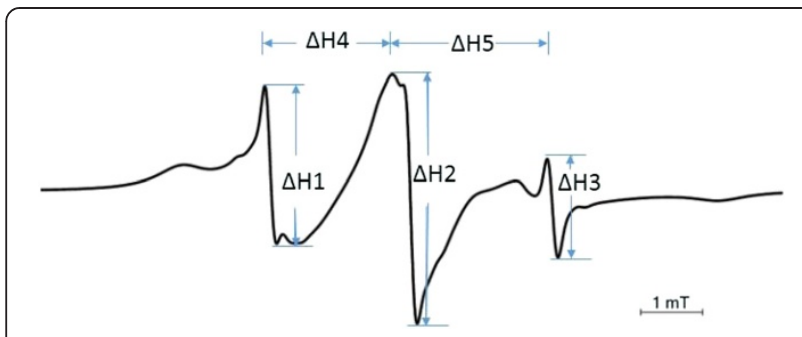

Figure 1 Selected values in a typical spectrum. $\Delta H 1 \Delta H 2 \Delta H 3$ show the relative intensity; $\Delta \mathrm{H} 4 \Delta \mathrm{H} 5$ show the relative peak widths.

$$
\mathrm{F}=\mathrm{d}_{\mathrm{i} 1} \mathrm{~V}_{1}+\mathrm{d}_{\mathrm{i} 2} \mathrm{~V}_{2}+\mathrm{d}_{\mathrm{iP}} \mathrm{V}_{\mathrm{P}}+\mathrm{C}
$$

Where $F$ is the discriminant function score, $d_{i}$ is the discriminant function coefficient, $\mathrm{V}$ is the score of the predictor variable and $\mathrm{C}$ is the discriminant function constant.

\section{Results}

As shown in Table 3, the five selected values (shown in Figure 1) were statistically different between the two groups. The $P$ values of the five parameters were all lf $s$ than 0.001 , which means they are significantly diff ${ }^{\circ}{ }^{2}$ between groups. Linear discriminant analysis w'as us ' based on the five selected parameters.

Table 4 shows the accuracy of the discrisinant nction coefficient for all the predictor varia les which were included in the study, from which the 1 . hest accurate values were included for the gener: $\sim n$ of discriminant function. The discriminant analysis rior.uced the best

Table 3 Medians and sta:1dard viation of the variables analyzed and means an standiard deviations of Ln-transformed lev._!s of s. cted values

\begin{tabular}{|c|c|c|c|c|c|c|}
\hline a) & & $l+1$ & $\Delta \mathrm{H} 2$ & $\Delta \mathrm{H} 3$ & $\Delta \mathrm{H} 4$ & $\Delta \mathrm{H} 5$ \\
\hline Group I & $M F \quad$ I & $17 \% 4$ & 122952 & 56825 & 15.3 & 15.378 \\
\hline$(n=141)$ & מ- & .4751 & 14729 & 25265 & 0.078 & 0.114 \\
\hline Group II & Mea. & 64398 & 71980 & 43411 & 15.192 & 15.362 \\
\hline$(n=180)$ & SD & 11498 & 12072 & 6379 & 0.051 & 0.086 \\
\hline$P$ value & & $<0.001$ & $<0.001$ & $<0.001$ & $<0.001$ & $<0.001$ \\
\hline b) & & $\operatorname{Ln} \Delta \mathrm{H} 1$ & $\operatorname{Ln} \Delta \mathrm{H} 2$ & $\operatorname{Ln} \Delta \mathrm{H} 3$ & $\operatorname{Ln} \Delta \mathrm{H} 4$ & $\operatorname{Ln} \Delta \mathrm{H} 5$ \\
\hline Group I & Median & 11.657 & 11.697 & 10.913 & 2.728 & 2.73 \\
\hline$(n=141)$ & SD & 0.223 & 0.219 & 0.266 & 0.007 & 0.005 \\
\hline Group II & Median & 11.17 & 11.056 & 10.668 & 2.721 & 2.732 \\
\hline$(n=180)$ & SD & 0.17 & 0.186 & 0.149 & 0.003 & 0.006 \\
\hline$P$ value & & $<0.001$ & $<0.001$ & $<0.001$ & $<0.001$ & $<0.001$ \\
\hline
\end{tabular}

Group I, patients with chronic disease just after operation ( $n=142)$; Group II, healthy volunteers $(n=180) ; S D$ standard deviation.

a) is the original data.

b) is the data after $\mathrm{Ln}$-transformation. $\mathrm{Ln}$ is Logarithmic transformation. $\mathrm{AH} 1$ is changed into $\mathrm{Ln} \Delta \mathrm{H} 1$ after $\mathrm{Ln}$ Logarithmic transformation.
Table 4 Wilk's lambda to test the significance among the predictor variables

\begin{tabular}{ccccc}
\hline $\begin{array}{c}\text { Test of } \\
\text { function(s) }\end{array}$ & $\begin{array}{c}\text { Wilks' } \\
\text { lambda }\end{array}$ & Chi-square & $\begin{array}{c}\text { Degrees of } \\
\text { freedom }\end{array}$ & Significance \\
\hline 1 & 0.200 & 509.437 & 5 & 0.002 \\
\hline
\end{tabular}

discriminant functions and the predictor variables included in the functions were $\Delta \mathrm{H} 1 \Delta \mathrm{r} i 2 \Delta \mathrm{H} 3 \Delta \mathrm{H} 4$ and $\Delta \mathrm{H} 5$ based on the greatest univariate $\mathrm{d}_{\mathrm{l}}$ inir ant coefficient. Before the formula was calcula $i$ with the greatest univariate discriminart a 'ffici nt, they were subjected to a test of signific ince usir ${ }_{\llcorner}$, Wilks' lambda. It was found the entire assignt predi tor variables showed statistical significance at < $<\ldots$ ( Table 4).

The Fisher's discri ninant ${ }_{i}$ ctions were as follows:

$$
\begin{aligned}
\mathrm{F} 1= & \left.338.9^{\wedge} \Delta \mathrm{H} 1\right\urcorner \quad 8328.145 \Delta \mathrm{H} 2-103.109 \Delta \mathrm{H} 3 \\
& +\quad \cdot 42 . \quad 234 \Delta \mathrm{H} 4+265.178 \Delta \mathrm{H} 5-255051.924 \\
\mathrm{~F} 2= & 3 \% . \quad 15 \Delta \mathrm{H} 1+88226.653 \Delta \mathrm{H} 2-116.781 \Delta \mathrm{H} 3 \\
& -96324.452 \Delta \mathrm{H} 4+259.369 \Delta \mathrm{H} 5-254166.845
\end{aligned}
$$

$\mathrm{Th}_{1}$ value obtained using discriminant function for c. er patients and healthy people is calculated, respectvely. This shows that this discriminant function formula can accurately identify cancer in this population. To access whether it is possible to generate accurate cancer diagnosis models from data collected for this study, discriminant functions were calculated and tested using cross-validation. This was performed using SPSS, and the leave-one-out method was chosen to calculate the cross-validation error rate (Table 5). The discriminant

\begin{tabular}{|c|c|c|c|c|c|}
\hline \multicolumn{6}{|c|}{ Classification results ${ }^{a, b}$} \\
\hline & & \multirow[t]{2}{*}{ Group } & \multicolumn{2}{|c|}{$\begin{array}{l}\text { Predicted group } \\
\text { membership }\end{array}$} & \multirow[t]{2}{*}{ Total } \\
\hline & & & 1 & 2 & \\
\hline \multirow[t]{4}{*}{ Original } & Count & 1 & 128 & 13 & 141 \\
\hline & & 2 & 21 & 159 & 180 \\
\hline & $\%$ & 1 & 90.8 & 9.2 & 100.0 \\
\hline & & 2 & 11.7 & 88.3 & 100.0 \\
\hline \multirow[t]{4}{*}{ Cross-validated $^{c}$} & Count & 1 & 124 & 17 & 141 \\
\hline & & 2 & 25 & 155 & 180 \\
\hline & $\%$ & 1 & 87.9 & 12.1 & 100.0 \\
\hline & & 2 & 13.9 & 86.1 & 100.0 \\
\hline
\end{tabular}
function used in the present study describes the optimal separation between the patients and healthy controls,

Table 5 Classification accuracy checked using crossvalidation for the developed discriminant function

${ }^{a} 89.4 \%$ of original grouped cases were correctly classified; ${ }^{b} 86.9 \%$ of crossvalidated grouped cases correctly classified; 'cross-validation is done only for those cases in the analysis. In cross-validation, each case is classified by the functions derived from all cases other than that case. 
and also shows that there are significant differences between them. This is substantiated by the classification accuracy of functions provided in Table 5. Hence, the original grouped cases correctly classified were $89.4 \%$.

\section{Discussion}

Albumin is the single most abundant protein in nonpathogenic plasma, comprising approximately two-thirds of total plasma proteins $[4,9,11]$. This study shows that the ability of albumin to bind FA is significantly altered in patients with colorectal cancer. This modification is likely caused by the presence of bioactive peptides and other substances from tumor tissue $[5,12,14]$. The shape of the EPR spectrum reflects the state of the spin probe molecules, such as characteristics of its molecular motion and electrical and magnetic fields in the surrounding environment $[11,15,16]$. Results of recent application of EPR spectroscopy in animal models and humans suggest that EPR has great diagnostic potential [9-11].

Discriminant functions have become a widely used method for disease discrimination [12]. Stepwise discriminant function analysis was applied which calculates the optimum combination of variables for discriminant function and weighs them to reflect their contribution $\alpha$ the determination [12,13]. A deficiency of the $\mathrm{cl}^{-} \mathrm{n}^{2}$ study was the significant difference in physical crılitic between healthy individuals and patients witt c 'recta! cancer. Postoperative patients only represer... part . 'the patients with colorectal cancer. The effer of chemotherapy, which might have significant influt $\supseteq$ or $_{\text {. tumor- }}$ related metabolite binding to album [15,1\%], as well as EPR spectral differences caused by $u_{1}$. or stage and localization $[18,19]$, have not 'see analyzed here. Automation of the pipetting and tiln it n...ps would also probably enhance the precis: - of the, rocedure [11].

\section{Conclusions}

The obtained res \& sh $\mathrm{Jw}$ that cancer-associated alterations to abu ain, n be assessed by spin-label EPR $[9,11]$. Usiı _ . 1u . . linear discriminant analysis we were able to develo ${ }_{1}$ a mathematical model allowing for identification of colorectal cancer patients with an $89.4 \%$ success rate based on fives values (of both relative intensity and peak width) which are obtained from the EPR spectrum. The potential applications for this diagnostic technique are significant and represent a cost-effective means for screening patients with cancer $[11,19]$. Further studies should take place in order to investigate all stages of colorectal cancer patients.

\section{Statement}

The study was approved by the local ethical committee and all individuals provided written informed consent for study participation.

\section{Abbreviations}

EPR: Electron paramagnetic resonance; FA: Fatty acids; HSA: Human serum albumin.

\section{Competing interests}

The authors declare that they have no competing interests.

\section{Authors' contributions}

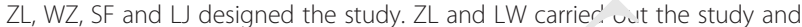
interpreted the results. ZL wrote the manuscript. All ? hor read and approved the final manuscript.

Received: 13 August 2013 Accepted: 29 Alis + 2013

Published: 11 September 2013

\section{References}

1. Ferlay J, Parkin DM, Steliaro'va iche. _umates of cancer incidence and mortality in Europs. In 200c ir J Cancer 2010, 46(4):765-781.

2. Chalya PL, McHembe ir Mabula J., Rambau PF, Jaka H, Koy M, Mkongo E, Masalu N: Clinic pat, oloy. 'patterns and challenges of management of colorectal can - - a resou. c-limited setting: a Tanzanian experience. World J Surc 'ncol n13, 11(1):88-97.

3. Duffy MJ, van . ' 'n $\mathrm{A}$, r aglund C, Hansson L, Klapdor R, Lamerz R, Nilsson O, Sturgeon C, Tc. ' 'an O: Tumor markers in colorectal cancer: European Group - mor inarkers (EGTM) guidelines for clinical use. Eur I Cancer 2007, 4. (c):13<-3-1360.

4. Peters T ir: All About Albumin: Biochemistry, Genetics, and Medical mplications. California: Academic Press; 1995.

tzhals P, Havelund S, Jonassen I, Kiehr B, Larsen UD, Ribel U, $N$ arkussen J: Albumin binding of insulins acylated with fatty acids: characterization of the ligand-protein interaction and correlation between binding affinity and timing of the insulin effect in vivo. Biochem J 1995, 312(Pt 3):725-731.

6. Curry S, Mandelkow H, Brick P, Franks N: Crystal structure of human serum albumin complexed with fatty acid reveals an asymmetric distribution of binding sites. Nat Struct Biol 1998, 5:827-835.

7. Mehta Al, Ross S, Lowenthal MS, Fusaro V, Fishman DA, Petricoin EF 3rd, Liotta LA: Biomarker amplification by serum carrier protein binding. Dis Markers 2003, 19(1):1-10.

8. Shenkar MG, Rananavare B, Freed JH: ESR studies of stearic acid binding to bovine serum albumin. Biochim Biophys Acta 1990, 1036(3):228-236.

9. Bhattacharya AA, Grüne T, Curry S: Crystallographic analysis reveals common modes of binding of medium and long-chain fatty acids to human serum albumin. J Mol Biol 2000, 303(5):721-732.

10. Seidel P, Gurachevsky A, Muravsky V, Schnurr K, Seibt G, Matthes G: Recognition of malignant processes with neural nets from ESR spectra of serum albumin. Z Med Phys 2005, 15(4):265-272.

11. Kazmierczak SC, Gurachevsky A, Matthes G, Muravsky V: Electron spin resonance spectroscopy of serum albumin: a novel new test for cancer diagnosis and monitoring. Clin Chem 2006, 52(11):2129-2134.

12. Gammerman A, Nouretdinov I, Burford B, Chervonenkis A, Vovk V, Luo Z: Clinical mass spectrometry proteomic diagnosis by conformal predictors. Stat Appl Genet Mol Biol 2008, 7(2):Article13.

13. de Noo ME, Mertens BJ, Ozalp A, Bladergroen MR, van der Werff MP, van de Velde CJ, Deelder AM, Tollenaar RA: Detection of colorectal cancer using MALDI-TOF serum protein profiling. Eur J Cancer 2006, 42(8):1068-1076.

14. Kalnina I, Kurjane N, Kirilova E, Klimkane L, Kirilov G, Zvagule T: Correlation of altered blood albumin characteristics and lymphocyte populations to tumor stage in gastrointestinal cancer patients. Cancer Biomark 2010, 7(2):91-99.

15. Berezin MY, Lee H, Akers W, Nikiforovich G, Achilefu S: Ratiometric analysis of fluorescence lifetime for probing binding sites in albumin with nearinfrared fluorescent molecular probes. Photochem Photobiol 2007, 83(6):1371-1378

16. Gurachevsky A, Muravsky V, Matthes G: Changes in serum albumin measured by electron spin resonance: in vitro diagnostic EPR test. Proc Int Soc Magn Reson Med 2007, 15:1323.

17. Rhodes CJ: Electron spin resonance. Part one: a diagnostic method in the biomedical sciences. Sci Prog 2011, 94(1):16-96. 
18. Gurachevsky A, Kazmierczak SC, Jörres A, Muravsky V: Application of spin label electron paramagnetic resonance in the diagnosis and prognosis of cancer and sepsis. Clin Chem Lab Med 2008, 46(9):1203-1210.

19. Gelos M, Hinderberger D, Welsing E, Belting J, Schnurr K, Mann B: Analysis of albumin fatty acid binding capacity in patients with benign and malignant colorectal diseases using electron spin resonance (ESR) spectroscopy. Int J Colorectal Dis 2010, 25(1):119-127.

doi:10.1186/1477-7819-11-223

Cite this article as: Liu et al:: Changes in the electron paramagnetic resonance spectra of albumin-associated spin-labeled stearic acid as a diagnostic parameter of colorectal cancer. World Journal of Surgical Oncology 2013 11:223.

\section{Submit your next manuscript to BioMed Central and take full advantage of:}

- Convenient online submission

- Thorough peer review

- No space constraints or color figure charges

- Immediate publication on acceptance

- Inclusion in PubMed, CAS, Scopus and Google Scholar

- Research which is freely available for redistribution 